\title{
Parasitism patterns and the size-fecundity relationship in the acoustically orienting dipteran parasitoid Ormia ochracea
}

\author{
Gita R. Kolluru and Marlene Zuk
}

\begin{abstract}
Female parasitoids are expected to distribute offspring among hosts in a manner that maximizes fitness. Several theoretical and empirical studies have focussed on clutch-size patterns in hymenopteran parasitoids. In contrast, dipteran parasitoids, which differ from hymenopterans in potentially important ways, have received little attention. The phonotactic tachinid fly Ormia ochracea has been intensively studied for its effects on host crickets, and has recently been the subject of studies of its own reproductive biology. This work suggests a negative relationship between clutch size and progeny fitness (consistent with hymenopterans), but no adjustment of clutch size to host size (different from hymenopterans). However, the repeatability of these patterns and the relationship between fly size and fitness remain to be demonstrated. We examined clutch sizes of $O$. ochracea larvae in the cricket Teleogryllus oceanicus. Most clutches were smaller than a cricket can support to pupation. Smaller clutches yielded larger offspring and larger wild-caught flies had higher fecundity, supporting the idea that small clutches yield higher fitness. However, although parasitised male crickets were slightly larger than unparasitised males, there was no correlation between cricket size and the number of larvae. Potential reasons for this departure from the patterns found in hymenopteran parasitoids are discussed.
\end{abstract}

\begin{abstract}
Résumé : On s'attend à ce que les parasitoïdes femelles répartissent leur progéniture parmi les hôtes de façon à maximiser leur fitness. Plusieurs études théoriques et empiriques ont été faites sur les fluctuations de la taille des pontes chez les hyménoptères parasitoïdes. En revanche, les diptères parasitoïdes, qui diffèrent potentiellement des hyménoptères sous plusieurs aspects importants, ont été peu étudiés. Les effets de la mouche tachinide phonotactique Ormia ochracea sur des grillons hôtes ont fait l'objet d'études détaillées et, plus récemment, la biologie de la reproduction de ce diptère a été examinée. Ces résultats indiquent l'existence d'une corrélation négative entre la taille des pontes et le fitness de la progéniture (comme chez les hyménoptères), mais aucun ajustement de la taille des pontes en fonction de la taille des hôtes (différent de chez les hyménopteres). Cependant, la constance de ces patterns et la relation entre la taille des mouches et le fitness restent à démontrer. Nous avons étudié le nombre de larves issues de pontes chez le grillon Teleogryllus oceanicus. La plupart des pontes sont plus petites que ce que peut supporter un grillon jusqu'à la pupaison. Les pontes plus petites donnent des rejetons plus gros et les mouches plus grosses en nature ont une fécondité plus élevée, corroborant ainsi l'hypothèse que les petites pontes sont associées à un meilleur fitness. Cependant, bien que les grillons mâles parasités se soient avérés légèrement plus gros que les mâles non parasités, il n'y a pas de corrélation entre la taille du grillon et le nombre de larves. Les raisons possibles de cet écart entre les patterns observés chez les diptères et ceux observés chez les hyménoptères parasitoïdes font l'objet d'une discussion.
\end{abstract}

[Traduit par la Rédaction]

\section{Introduction}

Much attention has recently been given to oviposition decisions in parasitoid insects (Godfray et al. 1991; Hardy et al. 1992; Mayhew 1998). Female parasitoids are predicted to adjust clutch size to the species, life-history stage, parasite status, and body size of the host in such a way that the gain in fitness from each clutch is maximized (Lack 1947; Waage

Received December 1, 2000. Accepted April 2, 2001.

Published on the NRC Research Press Web site at http://cjz.nrc.ca on May 25, 2001.

G.R. Kolluru ${ }^{\mathbf{1 , 2}}$ and M. Zuk. Department of Biology, University of California, Riverside, Riverside, CA 92521, U.S.A.

${ }^{1}$ Corresponding author (e-mail: gkolluru@obee.ucla.edu). ${ }^{2}$ Present address: Department of Organismic Biology, Ecology and Evolution, University of California, 621 Charles E. Young Drive South, Los Angeles, CA 90095-1606, U.S.A.
1986; Speirs et al. 1991; Wellings 1991; Godfray 1994). Empirical studies of clutch-size variation have almost exclusively focussed on hymenopteran parasitoids (e.g., Vet et al. 1994; Schmid-Hempel and Schmid-Hempel 1996; Fidgen et al. 2000; Karamaouna and Copland 2000). In contrast, little has been reported on clutch-size patterns in tachinid fly parasitoids, despite their abundance (Eggleton and Belshaw 1992; Belshaw 1994; Feener and Brown 1997). Tachinids differ from hymenopterans in lacking the rigid ovipositor that provides information about host parasite status and quality, and in often depositing mobile planidia larvae rather than eggs (Askew 1971; Price 1975; Belshaw 1994; Adamo et al. 1995a). These differences may lead to uncertainty in the female parasitoid about the number of larvae entering a given host (Godfray 1994) and to differences in host use and clutch-size patterns.

Phonotactic flies in the tribe Ormiini, which locate and deposit larvae onto and around singing hosts such as crickets and katydids (Cade 1975), have received a great deal of 
attention with respect to their effects on host reproduction (Zuk et al. 1993, 1995; Allen 1995, 1998; Gray and Cade 1999b, 2000; Lehmann and Lehmann 2000). This work has led to an interest in the reproductive biology of the flies themselves (Walker and Wineriter 1991; Fowler and Martini 1993; Adamo et al. 1995a; Allen et al. 1999), the most wellstudied of which is Ormia ochracea Bigot. In the most detailed of these studies, Adamo et al. (1995a) found that both clutch size (the number of larvae deposited onto the host) and larval number (the number of larvae emerging from the host) were smaller than the maximum a host could support to pupation. Because larger clutches yielded smaller pupae that were less likely to eclose, these authors suggested that clutch sizes are selected to be small because of a negative relationship between clutch size and progeny fitness. However, this scenario requires a demonstration that larger flies have higher fitness (Adamo et al. 1995a). These authors also found that, unlike most hymenopterans, O. ochracea does not adjust clutch size to host cricket size.

To determine whether these patterns are repeatable among fly populations and to ascertain the relationship between adult fly size and fecundity, we examined parasitism patterns of $O$. ochracea in the Hawaiian archipelago, where the fly attacks the field cricket Teleogryllus oceanicus Le Guillou. We addressed the following questions: (i) How many larvae naturally occur in male crickets, and what is the maximum number of larvae a cricket can support to pupation? (ii) How frequently does superparasitism (parasitism of a host individual that is already infested) occur? (iii) Is the number of parasitoid larvae adjusted to host cricket body size? (iv) What is the relationship between adult female fly size and fecundity?

\section{Materials and methods}

\section{Study organisms}

To determine natural larval numbers and host body sizes, male T. oceanicus were collected by hand from the grounds of the Hilo (Hawai'i, 1991-1997) and Manoa (Oahu, 1993-1996) campuses of the University of Hawai'i and the Kauai Research Station of the University of Hawaíi College of Tropical Agriculture and Human Resources in Kauai (1993 and 1995). Although female crickets are occasionally parasitised, only data from males are included in this paper. The pronotum width of each cricket was measured with digital callipers to the nearest $0.01 \mathrm{~mm}$. Crickets were frozen and examined under a dissecting microscope at $40 \times$ magnification. The thoracic muscles and body cavity were inspected for fly larvae. The length of each larva was measured with callipers, and larvae were classified as planidia (first-stage larvae with chitinous areas appearing as black dots on their surface) and small (1-4 mm), medium (5-9 mm), and large ( $>9 \mathrm{~mm}$ ) larvae. It is impossible to determine with absolute certainty whether a field-collected cricket is superparasitised, and previous authors have used the stages of larvae in a cricket to assign superparasitism status (Adamo et al. 1995a, 1995b). We considered a cricket to be superparasitised if one or more larvae in the cricket were at least twice as long as any other larvae in the same cricket.

\section{Experimental infestation}

To examine pupation success we placed 3-5 larvae in each of 38 male crickets and examined how many larvae successfully reached pupation. Five of the flies used were wild-caught and two were obtained from a laboratory colony maintained by R.R. Hoy at Cornell
University. Crickets to be parasitised were anaesthetised with $\mathrm{CO}_{2}$ gas $(100 \%$ for approximately $10 \mathrm{~s})$ immediately before infestation. Larvae were dissected from the flies and a dissecting pin was used to transfer the mobile larvae onto the membranous area around the front legs of each cricket (Cade 1984). This number of larvae is within the natural range found in wild populations of $T$. oceanicus (Zuk et al. 1995).

Fly pupae used to determine the relationship between larval number and pupa size were obtained from a previous study in which male crickets were experimentally infested as described above. Pupae were frozen and pupal width was measured using digital callipers.

\section{Fly size and fecundity}

To determine the relationship between adult fly size and fecundity, gravid female $O$. ochracea were trapped on the grounds of the University of Hawai'i Hilo campus. These flies were attracted by using ceramic tiles coated with Tanglefoot ${ }^{\mathrm{TM}}$ insect trap coating and baited with tape-recorded synthesized T. oceanicus song. Wildcaught flies were removed from Tanglefoot-coated traps and frozen. Each fly was measured using a filar eyepiece (LASICO No. 1602-A10) mounted on a dissecting microscope to determine the distance between the eyes and thorax width. Wings were not measured because most flies lost their wings in the Tanglefoot. After measurements were completed, each fly's uterus was lysed and all larvae with a hardened exoskeleton were counted under the dissecting microscope.

\section{Results}

\section{Numbers of larvae in host crickets}

Naturally parasitiszd male crickets $(n=214)$ harboured an average of 1.8 larvae $(\mathrm{SD}=1.2)$. The distribution of infestation intensities shows that although the majority of crickets harboured only 1 or 2 larvae, some had up to 8 (Fig. 1). The size distribution shows that most were planidia or small larvae (Fig. 2). Only 10 cases of likely superparasitism were observed, representing $4.7 \%$ of parasitised males.

Body size (mean pronotum width) of male crickets varied among the three Hawaiian islands on which T. oceanicus occurs (ANOVA, $n=1130, F_{[2,1124]}=71.53, p=0.0001$ ). The pronotum width of parasitised male crickets was, on average, $0.1 \mathrm{~mm}$ larger than that of unparasitised males even when differences among islands were taken into account (ANOVA, $\left.n=1130, F_{[1,1124]}=9.10, p=0.0026\right)$. However, cricket body size (pronotum width) did not significantly predict the number of larvae in the cricket (regression, $n=200$ crickets; $R^{2}=0.003, F_{[1,198]}=0.61, p=0.44$; Fig. 3 ).

Because cricket song may be used by flies to discriminate among host individuals, we used data from Zuk et al. (1998) to test whether cricket body size influenced song. The T. oceanicus calling song includes a long chirp consisting of a train of sound pulses and a set of short chirps with two pulses each (Zuk et al. 1993; Fig. 4). We characterized cricket song by measuring 18 temporal elements (e.g., long and short chirp pulse durations, interpulse intervals, and pulse numbers) and the carrier frequency. The temporal song elements were collapsed into five principal components (for details of song-variation analyses see Zuk et al. 1998). Because song characteristics vary among the islands (Rotenberry et al. 1996), the effects of island and body size on song are confounded. Therefore, we performed an analysis of covariance (ANCOVA) with body size (pronotum 
Fig. 1. Frequency distribution of clutch sizes of the dipteran parasitoid Ormia ochracea in male crickets (Teleogryllus oceanicus). Numbers above the bars indicate sample sizes of crickets.

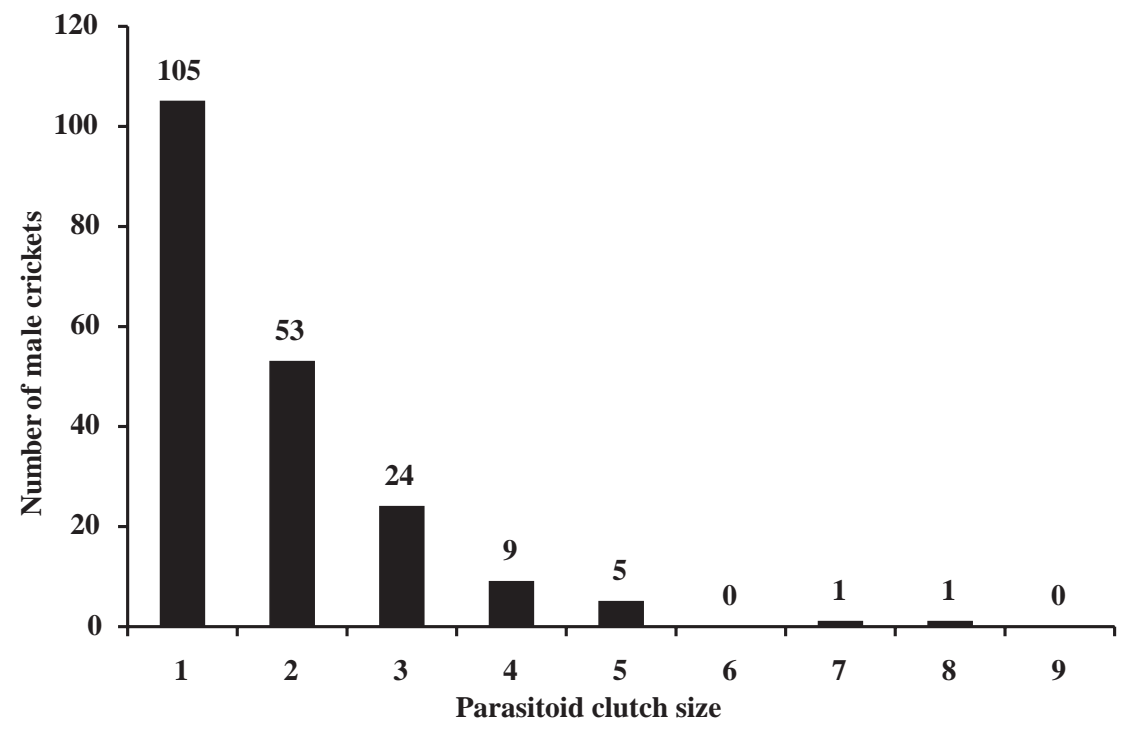

Fig. 2. Frequency distribution of $O$. ochracea size classes in male T. oceanicus.

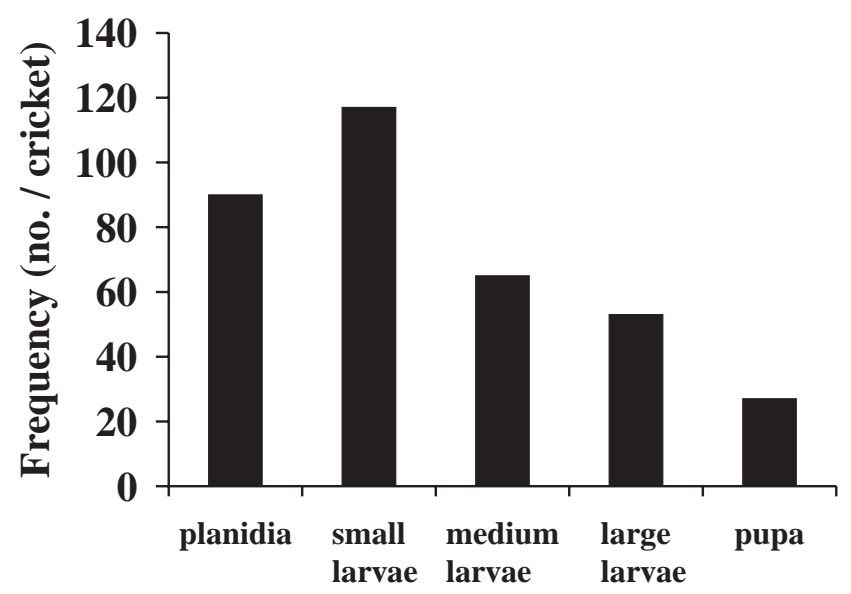

width) as the covariate, and found no effect of body size on the temporal song elements or on carrier frequency once the island effect was taken into account (ANCOVA, $n=252, p>$ 0.2 in all cases).

\section{Experimental infestation}

Although each experimentally infested male $(n=38)$ received 3-5 larvae, an average of only $2.13(\mathrm{SD}=0.93$, range $=1-4)$ pupae resulted from the infestations. Five larvae (each in a different cricket) did not emerge and were not counted. There was a negative relationship between clutch size and the width of the resulting pupae (correlation, $n=19, r=-0.57$, $p=0.01$; Fig. 5). This relationship was not a function of male cricket size, which did not significantly predict the number or size of pupae (regressions: number of pupae, $n=19$, $r=0.23, p=0.338$; pupal size, $n=19, r=0.32, p=0.176$ ).

\section{Fly size and fecundity}

The 284 adult female flies collected in Hawai'i in 1998 had an average of 165 sclerotised larvae $(\mathrm{SD}=192$, range $=$
Fig. 3. Relationship between host cricket size (pronotum width) and parasitoid clutch size. Points are means \pm 1 standard error. Numbers above the points indicate sample sizes of crickets.

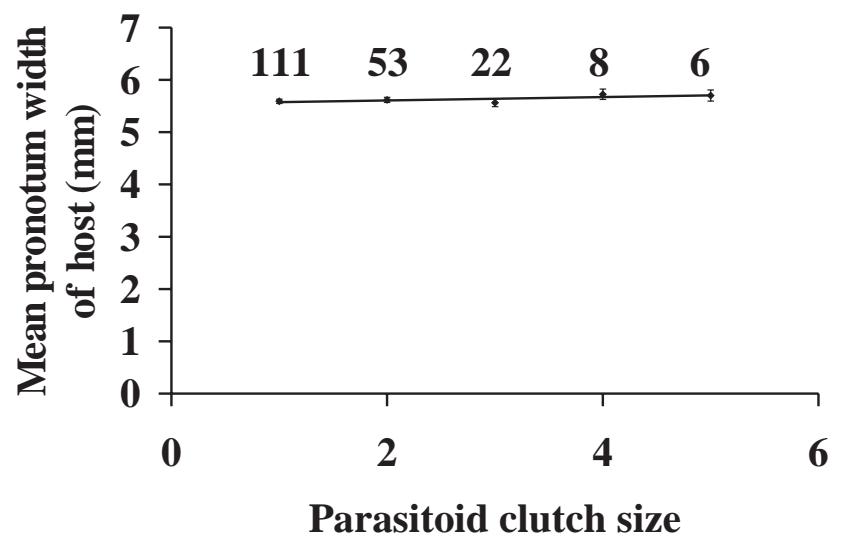

0-430). Fly thorax length and distance between the eyes were significantly correlated (Pearson's correlation: $r=0.76, p=$ 0.0001; Fig. 6). Each of the size measures was correlated with fecundity (Pearson's correlation: thorax length, $r=0.36$, $p=0.0001$; distance between the eyes, $r=0.32, p=0.0001$; Fig. 6).

\section{Discussion}

Although T. oceanicus crickets could support up to 4 $O$. ochracea larvae successfully to pupation, we found that the average clutch size was only about 2 larvae. Smaller clutches yielded larger pupae, and larger adult flies had higher fecundity. These results are in agreement with Adamo et al. (1995a) in demonstrating that natural O. ochracea clutch sizes are smaller than the maximum a cricket can support, and suggest that clutch sizes are small because of a negative relationship between clutch size and adult fly fitness. This indicates a similarity between hymenopteran and dipteran parasitoids in the factors influencing clutch-size 
Fig. 4. Sonogram of the typical calling song of T. oceanicus in Hawai'i.

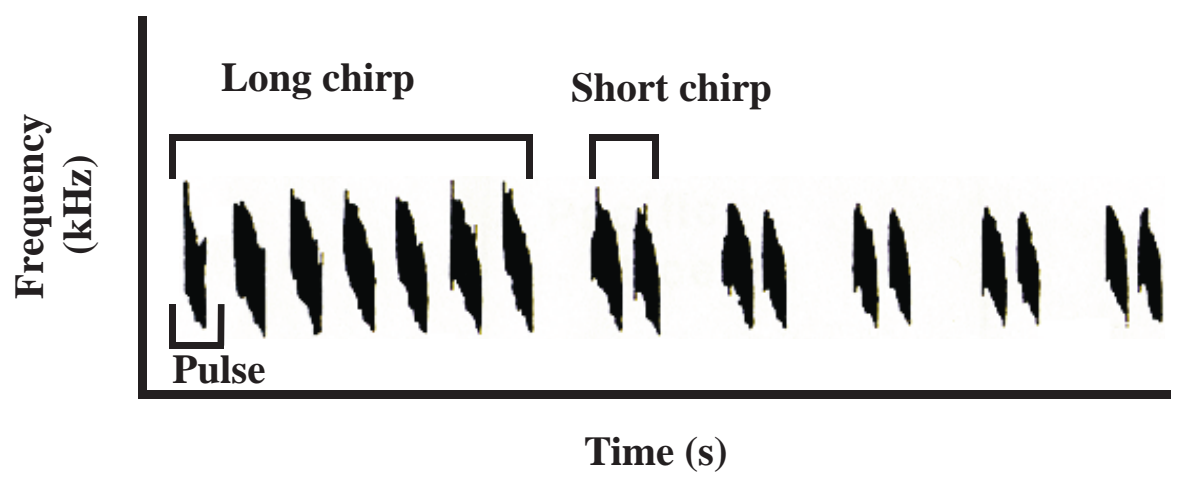

Fig. 5. Correlation between clutch size and resulting pupal width of O. ochracea in experimentally infested male $T$. oceanicus $(N=19$ male crickets). Points are means \pm 1 standard error.

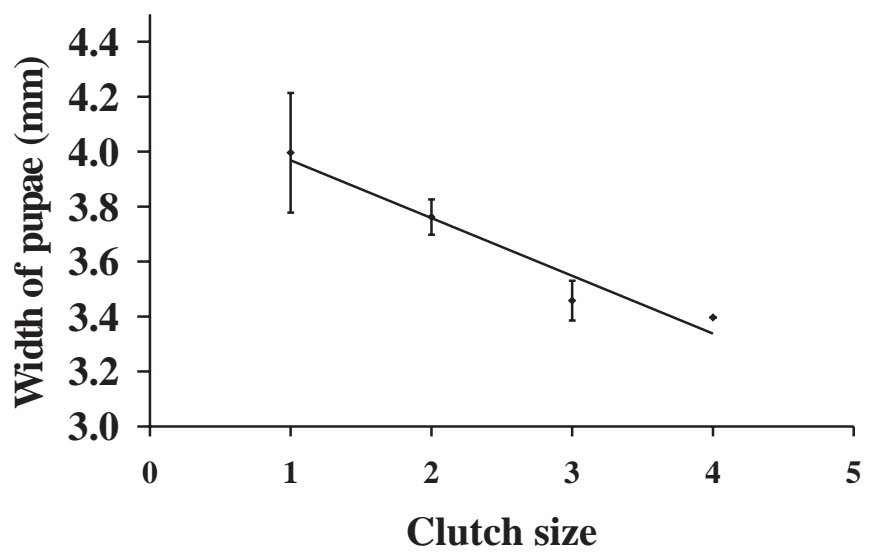

decisions (Vet et al. 1994; Adamo et al. 1995a; Allen and Pape 1996). However, data on the lifetime reproductive success of flies from clutches of different sizes are required to establish that natural selection acts to produce small clutches in tachinids.

Clutch sizes may also be reduced if large clutches waste female parasitoid time or eggs (Price 1975; Godfray 1994). However, it is unlikely that O. ochracea is time-limited during larviposition: the flies do not inject ovipositors or paralyse their hosts as do some hymenopterans (Feener and Brown 1997). Although the flies we captured had abundant larvae (only 50 of over 300 flies had fewer than 50 sclerotised larvae, and only one had no larvae), and calling male crickets are not abundant in Hawai'i, it is not known whether O. ochracea is egg- (or larva-) limited. Small clutches may also result from larval mortality. Although early-instar larvae may be successfully encapsulated by the cricket, we found little evidence of encapsulation, perhaps because tachinid larvae use the host-encapsulation response to build a breathing tube (Vinson 1990).

Parasitised crickets in this study were slightly larger than unparasitised crickets, suggesting that flies may select crickets above a threshold size. The most likely way this could occur is if cricket body size is indicated in the calling song. In some crickets, calling song varies with male size, and large males are more attractive to female crickets (Gryllus bimaculatus: Simmons 1987a, 1987b, 1988; but see Simmons
Fig. 6. Correlation between two measures of size of adult female O. ochracea (A) and between fecundity and thorax length (B). Data are from 284 wild-caught female flies.
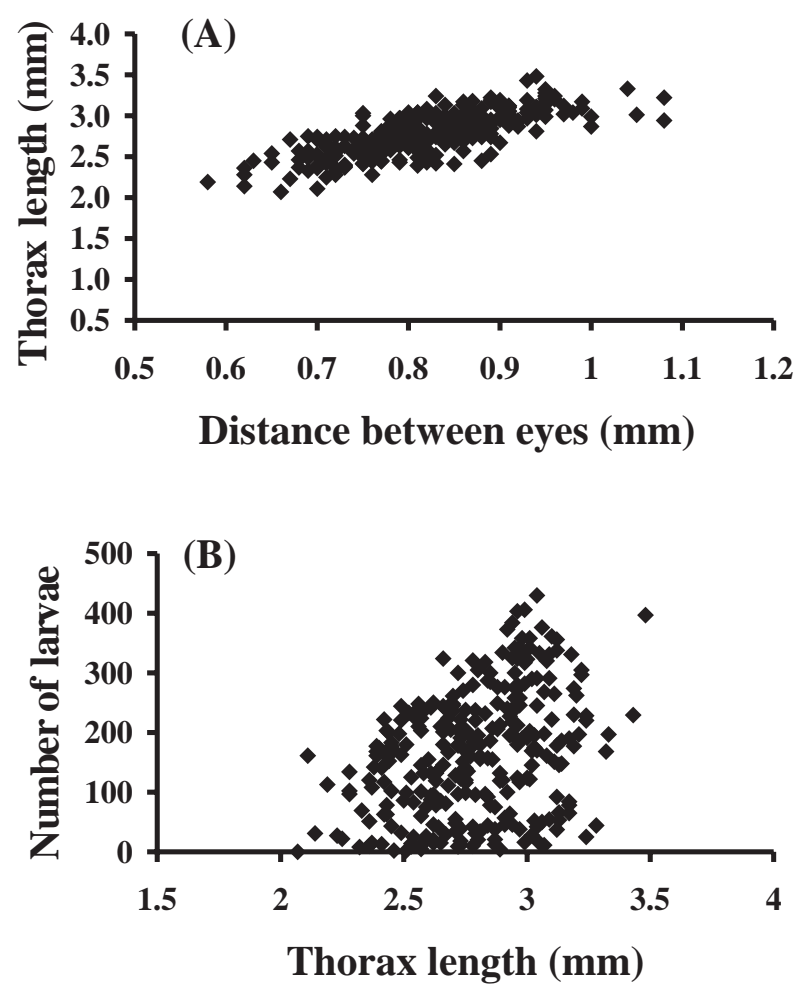

and Zuk 1992; G. campestris, Simmons 1992, 1995). However, in other crickets there is no correlation between body size and call parameters ( $G$. pennsylvanicus, Ciceran et al. 1994; G. integer, Gray and Cade 1999a). We found no relationship between body size and any of the song variables measured to date, including carrier frequency, temporal elements, and amount of calling per night (this paper; Kolluru 1999). However, some aspect of cricket song that we have not yet measured, or short-range visual cues, may be used by flies to locate larger crickets. Alternatively, flies may equally frequently parasitise small and large crickets, but larvae in smaller crickets may suffer higher mortality. In addition, it is also possible that the relatively small size difference $(0.1 \mathrm{~mm})$ between parasitised and unparasitised crickets is not biologically meaningful. 
Our data are in agreement with Adamo et al.'s (1995a) showing that fly clutch size is not adjusted to host body size. This contradicts studies of hymenopteran parasitoids, which largely support theoretical predictions that parasitoids will alter clutch size according to host quality (reviewed in Godfray 1994). There are several possible explanations for this discrepancy. Because female $O$. ochracea do not inject eggs into the host, they may be unable to accurately assess cricket size and adjust clutch size accordingly. In contrast, hymenopteran parasitoids use a variety of sensory cues to determine host quality both prior to and after insertion of the ovipositor (Wellings 1991; Godfray 1994). Although parasitoid flies are also able to incorporate host characteristics into oviposition decisions (e.g., Tanaka et al. 1999), phonotactic tachinids probably have limited contact with the host during larviposition. For example, Allen et al. (1999) showed that females of the phonotactic ormiine fly Homotrixa alleni did not physically contact hosts in over half of laboratory larviposition trials. Instead, flies sprayed larvae onto and around the hosts.

Ormia ochracea may also be unable to adjust clutch size because of its "mixed reproductive strategy" of both adult flies and larvae actively locating hosts (Feener and Brown 1997; Allen et al. 1999). The movement of larvae onto nearby hosts results in uncertainty about how many larvae will enter a given host (Adamo et al. 1995a), and may mask clutch-size adjustments made by the female fly. It is also possible that flies are adjusting clutch size to host quality, but that body size is not the measure of cricket quality important for flies. Instead, the number of "secondary hosts," male and female crickets attracted to the calling male, may be the important variable. There is evidence that flies and female crickets converge in their song preferences and that these preferences may select for localizability of the crickets (G.R. Kolluru, in preparation; Wagner 1996; Gray and Cade $1999 b)$. By choosing males with the preferred song characteristics, flies may be maximizing the number of hosts available to a given clutch of larvae. Finally, it is possible that flies adjusted the number of larvae placed on each cricket to the size of that cricket, but mortality within the host obscured the pattern when we and Adamo et al. (1995a) examined wild-caught crickets. Previous studies of Ormia spp. indicate only that between 1 and 10 larvae are deposited per cricket (Walker 1993; Adamo et al. 1995a), but do not address whether or not this correlates with cricket size.

The fecundity of wild-caught female $O$. ochracea in this study was within the range found in other ormiine flies (Fowler 1987; Fowler and Garcia 1987; Wineriter and Walker 1990). In laboratory tests, female O. ochracea deposited approximately 9 larvae per cricket ( 3 onto the cricket and 6 onto the surrounding area; Adamo et al. 1995a). This is considerably less than the number of larvae in a female fly and supports the idea that flies parasitise multiple hosts in a lifetime. Therefore, the decision of how many offspring to place on a given host may be influenced by the costs of missed opportunities to larviposit on other hosts. Godfray (1994) emphasises that clutch sizes will be small if the benefits of moving to a new host outweigh the benefits of depositing the maximum number of offspring in the current host.

Although our method of detecting superparasitism was conservative, and was possibly only sensitive to multiple parasitism events separated by a significant amount of time, our criterion was less conservative than that employed by Adamo et al. (1995a). Nevertheless, superparasitism rates in flies in Hawai'i were much lower than those authors found. Further understanding of superparasitism, and clutch size in general, requires the determination of host-encounter rates, which are known to influence clutch size (Charnov and Skinner 1985; Nakamura 1997). Although host-encounter rates are difficult to obtain for field cricket populations because both noncalling males and females may be parasitised, future studies of clutch size in $O$. ochracea should attempt to incorporate host-encounter rates into field assessments of the consequences of oviposition decisions (e.g., Bennett and Hoffmann 1998; Ellers et al. 1998).

\section{Acknowledgements}

We thank J.T. Rotenberry for assistance with data collection and analysis, D.K. Price for the use of laboratory facilities in Hawai'i, R.R. Hoy for supplying us with parasitoid flies, K. Kettleson and the staff at the University of Hawai' $i$ for assistance in the field, and M.A. Chappell, N.M. Waser, and three anonymous reviewers for their comments on the manuscript. This research was supported by the Animal Behavior Society and the National Science Foundation (IBN-9902255 and DEB-9257749).

\section{References}

Adamo, S.A., Robert, D., Perez, J., and Hoy, R.R. 1995a. The response of an insect parasitoid, Ormia ochracea (Tachinidae), to the uncertainty of larval success during infestation. Behav. Ecol. Sociobiol. 36: 111-118.

Adamo, S.A., Robert, D., and Hoy, R.R. 1995b. Effects of a tachinid parasitoid, Ormia ochracea, on the behaviour and reproduction of its male and female field cricket hosts (Gryllus spp.). J. Insect Physiol. 41: 269-277.

Allen, G.R. 1995. The biology of the phonotactic parasitoid, Homotrixa sp. (Diptera: Tachinidae), and its impact on the survival of male Sciarasaga quadrata (Orthoptera: Tettigoniidae) in the field. Ecol. Entomol. 20: 103-110.

Allen, G.R. 1998. Diel calling activity and field survival of the bushcricket, Sciarasaga quadrata (Orthoptera: Tettigoniidae): a role for sound-locating parasitic flies? Ethology, 104: 645-660.

Allen, G.R., and Pape, T. 1996. Description of female and biology of Blaesoxipha ragg Pape (Diptera: Sarcophagidae), a parasitoid of Sciarasaga quadrata Rentz (Orthoptera: Tettigoniidae) in Western Australia. Aust. J. Entomol. 35: 147-151.

Allen, G.R., Kamien, D., Berry, O., Byrne, P., and Hunt, J. 1999. Larviposition, host cues, and planidial behavior in the soundlocating parasitoid fly Homotrixa alleni (Diptera: Tachinidae). J. Insect Behav. 12: 67-79.

Askew, R.R. 1971. Parasitic insects. American Elsevier Publishing Co., Inc., New York.

Belshaw, R. 1994. Life history characteristics of Tachinidae (Diptera) and their effect on polyphagy. In Parasitoid community ecology. Edited by B.A. Hawkins and W. Sheehan. Oxford University Press, Oxford. pp. 145-162.

Bennett, D.M., and Hoffmann, A.A. 1998. Effects of size and fluctuating asymmetry on field fitness of the parasitoid Tricho- 
gramma carverae (Hymenoptera: Trichogrammatidae). J. Anim. Ecol. 67: 580-591.

Cade, W.H. 1975. Acoustically orienting parasitoids: fly phonotaxis to cricket song. Science (Washington, D.C.), 190: 1312-1313.

Cade, W.H. 1984. Effects of fly parasitoids on nightly duration of calling in field crickets. Can. J. Zool. 62: 226-228.

Charnov, E.L., and Skinner, S.W. 1985. Complementary approaches to the understanding of parasitoid oviposition decisions. Environ. Entomol. 14: 383-391.

Ciceran, M., Murray, A.-M., and Rowell, G. 1994. Natural variation in the temporal patterning of calling song structure in the field cricket Gryllus pennsylvanicus: effects of temperature, age, mass, time of day, and nearest neighbour. Can. J. Zool. 72: 38-42.

Eggleton, P., and Belshaw, R. 1992. Insect parasitoids: an evolutionary overview. Philos. Trans. R. Soc. Lond. B Biol. Sci. 337: $1-20$.

Ellers, J., van Alphen, J.J.M., and Sevenster, J.G. 1998. A field study of size-fitness relationships in the parasitoid Asobara tabida. J. Anim. Ecol. 67: 318-324.

Feener, D.H., Jr., and Brown, B.V. 1997. Diptera as parasitoids. Annu. Rev. Entomol. 42: 73-97.

Fidgen, J.G., Eveleigh, E.S., and Quiring, D.T. 2000. Influence of host size on oviposition behaviour and fitness of Elachertus cacoeciae attacking a low-density population of spruce budworm Choristoneura fumiferana larvae. Ecol. Entomol. 25: 156-164.

Fowler, H.G. 1987. Field behavior of Euphasiopteryx depleta (Diptera: Tachinidae): phonotactically orienting parasitoids of mole crickets (Orthoptera: Gryllotalpidae: Scapteriscus). J. N.Y. Entomol. Soc. 95: 474-480.

Fowler, H.G., and Garcia, C.R. 1987. Attraction to synthesized songs and experimental and natural parasitism of Scapteriscus mole crickets (Orthoptera: Gryllotalpidae) by Euphasiopteryx depleta (Diptera: Tachinidae). Rev. Bras. Biol. 47: 371-374.

Fowler, H.G., and Martini, A.M.Z. 1993. Larval dispersion of Ormia depleta (Towns.) (Dipt., Tachinidae). J. Appl. Entomol. 115: $107-110$.

Godfray, H.C.J. 1994. Parasitoids: behavioral ecology and evolutionary ecology. Princeton University Press, Princeton, N.J.

Godfray, H.C.J., Partridge, L., and Harvey, P.H. 1991. Clutch size. Annu. Rev. Ecol. Syst. 22: 409-429.

Gray, D.A., and Cade, W.H. 1999a. Quantitative genetics of sexual selection in the field cricket, Gryllus integer. Evolution, 53: 848-854.

Gray, D.A., and Cade, W.H. 1999b. Sex, death and genetic variation: natural and sexual selection on cricket song. Proc. R. Soc. Lond. B Biol. Sci. 266: 707-709.

Gray, D.A., and Cade, W.H. 2000. Senescence in field crickets (Orthoptera; Gryllidae): examining the effects of sex and a sexbiased parasitoid. Can. J. Zool. 78: 140-143.

Hardy, I.C.W., Griffiths, N.T., and Godfray, H.C.J. 1992. Clutch size in a parasitoid wasp: a manipulation experiment. J. Anim. Ecol. 61: 121-129.

Karamaouna, F., and Copland, M.J.W. 2000. Host suitability, quality and host size preference of Leptomastix epona and Pseudaphycus flavidulus, two endoparasitoids of the mealybug Pseudococcus viburni, and host size effect on parasitoid sex ratio and clutch size. Entomol. Exp. Appl. 96: 149-158.

Kolluru, G.R. 1999. Variation and repeatability of calling behavior in crickets subject to a phonotactic parasitoid fly. J. Insect Behav. 12: 611-626.

Lack, D. 1947. The significance of clutch size. Ibis, 89: 309-352.

Lehmann, G.U.C., and Lehmann, A.W. 2000. Spermatophore char- acteristics in bushcrickets vary with parasitism and remating interval. Behav. Ecol. Sociobiol. 47: 393-399.

Mayhew, P.J. 1998. Offspring size-number strategy in the bethylid parasitoid Laelius pedatus. Behav. Ecol. 9: 54-59.

Nakamura, S. 1997. Clutch size regulation and host discrimination of the parasitoid fly, Exorista japonica (Diptera: Tachinidae). Appl. Entomol. Zool. 32: 283-291.

Price, P.W. 1975. Reproductive strategies of parasitoids. In Evolutionary strategies of parasitic insects and mites. Edited by P.W. Price. Plenum Press, New York. pp. 87-111.

Rotenberry, J.T., Zuk, M., and Hayes, C. 1996. Phonotactic parasitoids and cricket song structure: an evaluation of alternative hypotheses. Evol. Ecol. 10: 233-243.

Schmid-Hempel, R., and Schmid-Hempel, P. 1996. Host choice and fitness correlates for conopid flies parasitising bumblebees. Oecologia, 107: 71-78.

Simmons, L.W. 1987a. Female choice contributes to offspring fitness in the field cricket, Gryllus bimaculatus (De Geer). Behav. Ecol. Sociobiol. 21: 313-321.

Simmons, L.W. 1987b. Sperm competition as a mechanism of female choice in the field cricket, Gryllus bimaculatus. Behav. Ecol. Sociobiol. 21: 197-202.

Simmons, L.W. 1988. Male size, mating potential and lifetime reproductive success in the field cricket, Gryllus bimaculatus (De Geer). Anim. Behav. 36: 372-379.

Simmons, L.W. 1992. Sexual selection and body size in a natural population of the field cricket, Gryllus campestris. J. Orthoptera Res. 1: 12-13.

Simmons, L.W. 1995. Correlates of male quality in the field cricket, Gryllus campestris L.: age, size, and symmetry determine pairing success in field populations. Behav. Ecol. 6: 376-381.

Simmons, L.W., and Zuk, M. 1992. Variability in call structure and pairing success of male field crickets, Gryllus bimaculatus: the effects of age, size and parasite load. Anim. Behav. 44: 1145-1152.

Speirs, D.C., Sherratt, T.N., and Hubbard, S.F. 1991. Parasitoid diets: does superparasitism pay? Trends Ecol. Evol. 6: 22-25.

Tanaka, C., Kainoh, Y., and Honda, H. 1999. Physical factors in host selection of the parasitoid fly, Exorista japonica Townsend (Diptera: Tachinidae). Appl. Entomol. Zool. 34: 91-97.

Vet, L.E.M., Datema, A., Janssen, A., and Snellen, H. 1994. Clutch size in a larval-pupal endoparasitoid: consequences for fitness. J. Anim. Ecol. 63: 807-815.

Vinson, S.B. 1990. How parasitoids deal with the immune system of their host: an overview. Arch. Insect Biochem. Physiol. 13: 3-27.

Waage, J.K. 1986. Family planning in parasitoids: adaptive patterns of progeny and sex allocation. In Insect parasitoids. Edited by J. Waage and D. Greathead. Academic Press, London. pp. 63-95.

Wagner, W.E., Jr. 1996. Convergent song preferences between female field crickets and acoustically orienting parasitoid flies. Behav. Ecol. 7: 279-285.

Walker, T.J. 1993. Phonotaxis in female Ormia ochracea (Diptera: Tachinidae), a parasitoid of field crickets. J. Insect Behav. 6: 389-410.

Walker, T.J., and Wineriter, S.A. 1991. Hosts of a phonotactic parasitoid and levels of parasitism (Diptera: Tachinidae: Ormia ochracea). Fla. Entomol. 74: 554-559.

Wellings, P.W. 1991. Host location and oviposition on animals. In Reproductive behaviour of insects: individuals and populations. Edited by W.J. Bailey and J. Ridsdill-Smith. Chapman and Hall, London. pp. 75-107.

Wineriter, S.A., and Walker, T.J. 1990. Rearing phonotactic 
parasitoid flies (Diptera: Tachinidae, Ormiini, Ormia spp.). Entomophaga, 35: 621-632.

Zuk, M., Simmons, L.W., and Cupp, L. 1993. Calling characteristics of parasitized and unparasitized populations of the field cricket Teleogryllus oceanicus. Behav. Ecol. Sociobiol. 33: 339-343.

Zuk, M., Simmons, L.W., and Rotenberry, J.T. 1995. Acoustically- orienting parasitoids in calling and silent males of the field cricket Teleogryllus oceanicus. Ecol. Entomol. 20: 380-383.

Zuk, M., Rotenberry, J.T., and Simmons, L.W. 1998. Calling songs of field crickets (Teleogryllus oceanicus) with and without phonotactic parasitoid infection. Evolution, 52: 166-171. 